\title{
Disputas agrárias no fim dos Setecentos: a área Central da Mata mineira (1767-1800)
}

\section{Fernando Gaudereto Lamas}

Resumo: A intenção deste artigo é discutir as variadas formas de disputas em torno da terra ocorridas na área Central da Zona da Mata de Minas Gerais a partir da data oficial de sua ocupação (1767) e o final do século XVIII. Tais disputas foram ocasionadas especialmente pelas distintas formas de ocupação do solo (compra/venda, sesmarias e posse). Os resultados dessas disputas mostram-nos a importância da presença da administração colonial (atuando como mediadora dos conflitos), assim como indicam-nos questões referentes à peculiaridade nas formas de aquisição de terras na capitania de Minas durante os Setecentos.

Palavras-chave: Área Central da Zona da Mata mineira; Século XVIII; Disputas em torno da terra.

Abstract: The intention of this paper is to discuss the varied forms of disputes about land occurred in the Central area of Zona da Mata of Minas Gerais from the official date of its occupation (1767) and the late eighteenth century. These disputes were occasioned especially by the different forms of land occupation (purchase/sale, and possession of sesmarias). The results of these contests show the importance of the presence of the colonial administration (acting as a mediator of conflicts), as indicated in questions related to the peculiarity in the forms of land acquisition in Minas during the eighteenth century.

Keywords: Central Area of the Zona da Mata of Minas Gerais; Eighteenth century; Disputes about land.

\section{OCUPAÇÃO FRONTEIRIÇA E DOAÇÃO DE SESMARIAS}

Após espalhar-se a notícia a respeito do sucesso obtido pelo padre Manoel de Jesus Maria em pacificar e cristianizar os indígenas coroados e coropós, que habitavam o vale do rio Pomba, um grande afluxo de pessoas correu para a região atrás de terras férteis e, possivelmente, de ouro. A região onde agora se localizava o aldeamento de São Manoel já havia sido alvo de incursões no passado, protagonizadas principalmente por colonos ávidos em encontrar novas jazidas auríferas. Entretanto, a hostilidade dos indígenas locais criava uma barreira para a continuidade desse projeto; evidentemente, enquanto a extração de ouro e diamante continuou alta, a preocupação da administração colonial em apoiar a anexação de novas áreas foi bastante pequena, a não ser quando surgiam provas da existência de metais e pedras preciosas.

O próprio padre referenda essa ideia ao afirmar que

\footnotetext{
* Doutorando em História Econômica e Social pela Universidade Federal Fluminense (UFF) e professor do Colégio de Aplicação João XXIII, da Universidade Federal de Juiz de Fora (UFJF). Bolsista da CAPES e membro pesquisador do Projeto de Investigação Lands over Seas, coordenado pela Professora Doutora Márcia Maria Menendes Motta (Universidade Federal Fluminense) e pelo Professor Doutor José Vicente Serrão (Universidade Nova de Lisboa). E-mail: fernando.lamas@ufjf.edu.br.
} 
a precisão de novos colonos para estimular e dirigir as indústrias dos índios. $\mathrm{O}$ concurso de outros aventureiros que procuram melhorar de fortuna e terras, é verdade terem aumentado consideravelmente a população desta freguesia que já passam de mil. ${ }^{1}$

A carta escrita ao Bispo de Mariana em 1888 reflete o crescimento populacional oriundo do adensamento migratório. O rol dos confessados do Termo de Mariana indica um crescimento semelhante, apesar de apresentar-se maior conforme a tabela presente nos anexos. Analisando esse documento, podemos perceber que o crescimento populacional foi incessante. Em 1780, segundo dados enviados pelo padre Manoel de Jesus Maria, havia 1.179 pessoas na freguesia ${ }^{2}$, enquanto que no ano de 1782 , em seu início, foram contabilizadas 1.272 pessoas $^{3}$ e no final desse mesmo ano 1.535 pessoas. ${ }^{4}$ Três anos depois (1785), a população saltou para $1.760^{5}$ e no ano seguinte (1786) para $1.933 .^{6}$

Os dados populacionais da tabela elaborada por Ângelo Carrara indicam que em 1780 havia 1.182 pessoas na Freguesia de Rio Pomba e que, quando o padre Manoel de Jesus Maria escreveu, isto é, em 1788, havia 2.319 pessoas na mesma freguesia. Esse crescimento não cessou ao longo do século XVIII, uma vez que em 1792 esse número havia saltado para 2.968 e em 1795 para 3.625, atingindo em 1798 o número de 4.250. ${ }^{7}$ Esse crescimento demográfico ocorrido entre o fim da década de 1780 e o fim da década de 1790 deve ser analisado em comparação com o crescimento da Freguesia de Guarapiranga, uma vez que um número considerável de migrantes saiu daquela freguesia. No mesmo período, ou seja, entre 1780 e 1792, Guarapiranga conheceu uma diminuição significativa de sua população, já que saiu de 10.087, em 1780, atingiu 10.720 em 1787, e posteriormente, em 1788, caiu para 10.572 .

O gráfico 01 indica a variação populacional provocada pelas constantes migrações entre as freguesias ao longo da segunda metade do século XVIII. Por ele fica claro que a Freguesia de São Manoel do Rio Pomba cresceu significativamente entre os anos de 1780 e 1798, enquanto outras freguesias vizinhas de povoamento mais antigo decresceram no mesmo período. Guarapiranga (no gráfico apenas Piranga) e Infeccionado, por exemplo, apresentam uma grande e constante oscilação ao longo do tempo balizado pelo gráfico. Ambas as freguesias eram vizinhas de São Manoel de Rio Pomba, a tal ponto que alguns de seus moradores atuaram como padrinhos/madrinhas em batizados feitos pelo padre Manoel de Jesus Maria. Essa oscilação era fruto do processo migratório em direção às terras de rio Pomba, localizadas na área Central da Mata; tal migração por sua vez deu-se tanto por meio do aumento do número de doações de sesmarias na área quanto por meios alternativos, isto

\footnotetext{
${ }^{1}$ AHU-MG. 1788/11/30. Cx. 130, doc. 48. Carta do padre Manoel de Jesus Maria para o Bispo de Mariana, dando o seu parecer sobre o que os párocos cobravam de Conhecenças, fl. 03.

${ }^{2}$ Arquivo Eclesiástico da Arquidiocese de Mariana. Rol dos confessados (1780-1817), fl.01-02.

${ }^{3}$ Arquivo Eclesiástico da Arquidiocese de Mariana. Rol dos confessados (1780-1817), fl.05.

${ }^{4}$ Arquivo Eclesiástico da Arquidiocese de Mariana. Rol dos confessados (1780-1817), fl.07.

${ }^{5}$ Arquivo Eclesiástico da Arquidiocese de Mariana. Rol dos confessados (1780-1817), fl.10.

${ }^{6}$ Arquivo Eclesiástico da Arquidiocese de Mariana. Rol dos confessados (1780-1817), fl.12.

${ }^{7}$ CARRARA, Ângelo Alves. Minas e currais: produção rural e mercado interno de Minas Gerais (1674-1807). Juiz de Fora: EDUFJF, 2006, p. 324.
} 
é, migrantes que mesmo sem o título de propriedade deslocaram-se para a região em busca de novas oportunidades, uma vez que em áreas de matas fechadas, ou de sertões, a vistoria era menor e a chance de se estabelecer para, em um momento posterior solicitar a legalização das terras, era maior.

Gráfico 01: Movimentação populacional das freguesias

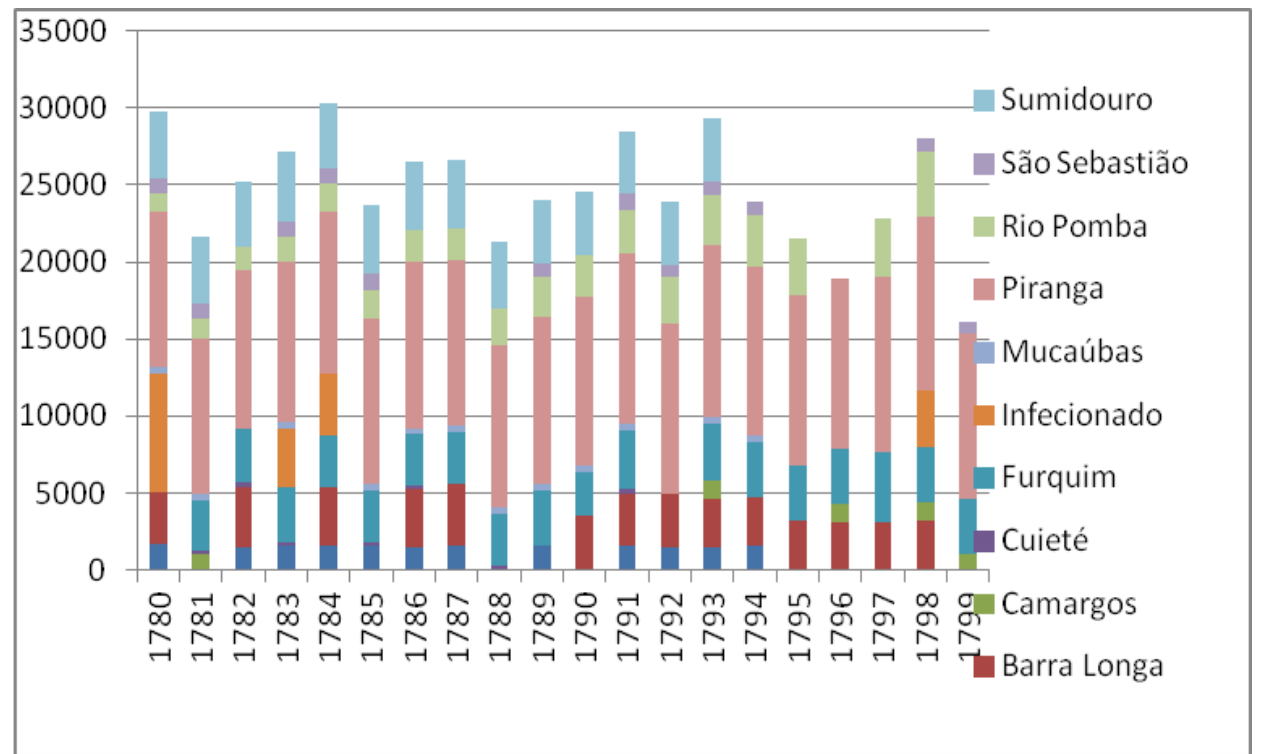

Fonte: CARRARA, Ângelo Alves. Minas e currais: produção rural e mercado interno de Minas Gerais (16741807). Juiz de Fora: EDUFJF, 2006, p. 324.

É interessante analisar que a ideia de adensamento populacional exclui a presença dos indígenas. Em um mapa de população feito no ano de 1776 e enviado pelo então governador D. Antônio de Noronha a Martinho de Melo e Castro, os dados referentes à Comarca de Vila Rica, que incluía também a cidade de Mariana e seu Termo, não fazem nenhuma menção à presença de indígenas. É relevante destacar que a documentação frisa que o referido mapa foi feito com base nas "taboas de população que deram os párocos das Freguesias com distinção de sexo, idade, mortos e nascidos, tudo pertencente ao ano de $1776 " .{ }^{8}$ Se por um lado causa estranheza, especialmente em função de um claro desacato a um dos objetivos mais preciosos da política pombalina em relação aos indígenas, isto é, incluí-los como habitantes da colônia, por outro lado revela-nos que a preocupação expressa pelo padre dez anos depois do envio do mapa populacional indica que o citado crescimento da população não se referia ao descimento de indígenas rumo ao aldeamento de São Manoel, mas à presença cada vez mais constante de migrantes oriundos naquele momento, principalmente da região mineradora. $O$ número de doações de sesmarias na área também aumentou significativamente em relação ao período imediatamente anterior. Se entre a década de 1750 até 1780 , momento que marcou a primeira etapa da colonização da área, o

\footnotetext{
${ }^{8}$ AHU-MG. 1778/01/28. Cx. 112, doc. 11. Carta de D. Antônio de Noronha, Governador das Minas, informando a Martinho de Melo e Castro, entre outros assuntos, sobre a remessa do mapa relativo aos habitantes da referida Capitania, fl. 05.
} 
número de sesmarias foi de $39^{9}$, a partir de 1780 até o final do século esse número saltou para $111^{10}$, representando não somente o crescimento demográfico, como também a maior participação da administração colonial em relação à área.

Em outra carta, o padre Manoel de Jesus Maria reclama justamente da excessiva participação da administração colonial no tocante à doação de sesmarias na região, a tal ponto que causava prejuízo aos indígenas que ele catequizava. Nesse documento, datado de 1799, Manoel de Jesus Maria reclama do grande afluxo de migrantes e afirma que a população da freguesia ultrapassava os três mil habitantes. ${ }^{11}$ Se levarmos em conta as opiniões do padre, em ambos os documentos temos um crescimento de duas mil pessoas em onze anos, número elevado para os padrões da época, especialmente para uma área que se encontrava na periferia da capitania de Minas e era de acesso relativamente complexo. Mesmo com as dificuldades impostas pela distância e pela dureza dos caminhos, os sertões do rio Pomba estavam sendo ocupados sistematicamente, como podemos verificar pelos pedidos de confirmação de sesmarias. Analisando a estrutura das solicitações de sesmarias, percebemos que todas pediam meia légua de terra, fato que corrobora o estudo de Márcia Motta, que percebeu que, entre 1795 e 1823, aproximadamente 75,52\% das solicitações correspondiam a essa medida. Mesmo analisando um período anterior, também encontramos em todas as solicitações a mesma medida (meia légua). Acima dela não foi encontrado nenhum pedido. A solicitação de confirmação de sesmarias em alguns casos apenas regularizava uma posse já praticada. Segundo Márcia Motta, a legislação agrária lusitana não caiu em um vazio total, uma vez que é possível perceber uma procura pela legalização da posse da terra. Ainda conforme a autora, "querendo ou não, os sesmeiros eram constrangidos a cumprir a lei ou ao menos lembrados de suas bases constitutivas". ${ }^{12}$ Esse fato fica evidente quando se analisa o caso de alguns membros da família Pires Farinho. $^{13}$

\footnotetext{
${ }^{9}$ Este dado foi extraído das seguintes fontes: APM. SC 90; SC 96; SC 106; SC 112; SC 119; SC 122; SC 140; SC 146; SC 172; SC 206 e AHU-MG. Cx. 107, doc. 44; Cx. 109, doc. 43; Cx. 64, doc. 51; Cx. 78, doc. 68; Cx. 73, doc. 08; Cx. 79, doc. 35; Cx. 101, doc. 62; Cx. 95, doc. 02; Cx.114, doc. 27; Cx. 113, doc. 41; Cx. 79, doc. 21; Cx. 90, doc. 55; Cx. 104, doc. 08; Cx. 104, doc. 09; Cx. 109, doc. 43 e também ACS. Livro de Registro de Sesmarias. 1. Ofício. Códice 07, doc. 283; 1. Ofício. Códice 06, doc. 233; 1. Ofício. Códice 07, doc. 294.

${ }^{10}$ Este dado foi extraído das seguintes fontes: APM. SC 256; SC 265; SC 275; SC 285; SC 286; SC 289; SC 234 e APM. C.C. Cx. 101, doc. 20493, rolo 531; CC Cx. 46, doc. 30274, rolo 515; e também AHU-MG. Cx. 140, doc. 37; Cx. 123, doc. 24.

${ }_{11}$ AHU-MG. 1799/08/27. Cx. 149, doc. 62. Carta de Manoel de Jesus Maria, vigário dos índios coropós e coroados, para D. Rodrigo de Souza Coutinho, expondo sobre o prejuízo para os índios na concessão de sesmarias pelo Governador das Minas, fl. 02.

${ }_{12}$ MOTTA, Márcia Maria Menendes. Direito à terra no Brasil: a gestação do conflito (1795-1824). São Paulo: Alameda, 2009, p. 136-137.

${ }^{13}$ O patriarca desta família foi Brás Pires Farinho, português nascido na Vila de Serpa, distrito e bispado de Beja, que migrou para as Minas Gerais no início do século XVIII, onde se casou com uma paulista chamada Sebastiana Cardoso de Mendonça, no ano de 1709. Cf. BUENO, Antônio Henrique da Cunha; BARATA, Carlos Eduardo de Almeida. Dicionário das famílias brasileiras vol. 2. São Paulo: Litografia Tucano, 1999, p. 1809. De seu casamento resultaram os seguintes filhos pela ordem de nascimento: Joana Pires Farinho, Ana Pires Farinho, Antônia Pires Farinho, Quitéria Francisca Pires Farinho, Liberata Pires, Marinha Pires Farinho, Clara Pires Farinho, Manoel Pires Farinho, Francisco Pires Farinho, Martinho Pires Farinho e Luiza Pires Farinho. Informações obtidas no seguinte endereço eletrônico:
} 
Nesse primeiro momento, essa família teve um papel de destaque na freguesia, tanto pela atuação de Francisco e Manoel Pires Farinho como diretores do aldeamento quanto como colonizadores da nova região, já que foram responsáveis pelo desbravamento da área, além de terem adquirido nela sesmarias. Clara Pires Farinho, irmã dos referidos diretores, morava no Xopotó com seu marido Manoel Leitão de Almeida, ao menos desde o final da década de 1760, pois participou, na condição de madrinha, do batizado de Brígida, índia filha de Antônia e Martinho, índios catecúmenos, em oito de maio de $1768 .{ }^{14} \mathrm{Em} 20$ de agosto de 1774, Clara Pires Farinho alcançou o título de sesmaria. ${ }^{15}$ Suas terras foram medidas e demarcadas, e situadas entre as de João Pedro de Frios Carneiro e as de Francisco Dutra Caldeira. ${ }^{16}$

Seguir as regras da época, isto é, executar a demarcação e a medição das sesmarias tinha um custo, que no caso em questão foi de $7 \$ 960$ (sete mil novecentos e sessenta réis). ${ }^{17}$ A mãe de Clara deixou em testamento a quantia de 174 mil e 908 réis para ser dividida entre Clara, Quitéria, Ana, Liberata e Antônia ${ }^{18}$, o que dava aproximadamente 35 mil réis para cada um, valor suficiente para pagar os custos da medição e demarcação de uma sesmaria. Entretanto, nem todos podiam arcar com esse tipo de despesa, o que pode explicar o baixo índice de demarcação e de medição na Capitania à época. ${ }^{19} \mathrm{O}$ marido de Clara, Manoel Leitão de Almeida, também obteve sesmarias no Xopotó, em 25 de agosto de 1774, isto é, apenas cinco dias depois de sua esposa. ${ }^{20}$ Suas terras também confrontavam com as de Francisco Dutra Caldeira ${ }^{21}$, sugerindo uma proximidade com as terras da esposa. O valor total das despesas com a medição e demarcação das terras de Manoel Leitão de Almeida ficou em $8 \$ 545$ (oito mil quinhentos e quarenta e cinco réis). ${ }^{22}$

Conforme dissemos antes, os custos para a legalização das terras não estavam ao alcance de muitos nessa época. Em um documento datado de 27 de agosto de 1799, um requerimento assinado por antigos moradores da região sem título de propriedade, ou seja, sem título de sesmarias, criticava o avanço de novos colonos que possuíam títulos. Nesse caso em particular, os não possuidores de títulos de sesmarias eram pessoas que, juntamente com o padre Manoel de Jesus Maria, haviam ocupado a região em seus primórdios, ou seja, concomitantemente ao estabelecimento do aldeamento de São Manoel

http://www.projetocompartilhar.org/Familia/PiresFarinho.htm. Acesso em: 14 jan. 2011, às 13 horas e sete minutos.

${ }^{14}$ Arquivo Eclesiástico da Paróquia de São Manoel de Rio Pomba. Livro de Registro de Batismos n. 1, fl. 02.

${ }^{15}$ Arquivo da Casa Setecentista. Livro de Registro de Sesmarias. 1.e Ofício. Códice 07, doc. 283, fl. 03.

${ }^{16}$ Arquivo da Casa Setecentista. Livro de Registro de Sesmarias. 1.o Ofício. Códice 07, doc. 283, fl. 06-07.

${ }^{17}$ Arquivo da Casa Setecentista. Livro de Registro de Sesmarias. 1.o Ofício. Códice 07, doc. 283, fl. 08.

${ }^{18}$ Arquivo da Casa Setecentista. Livro de Registro de Inventários. 2.o Ofício. Cx 89, auto 1920, fl. 15. Disponível em: http://www.projetocompartilhar.org/DocsMgMz/sebastianacardosa1757.htm. Acesso em: 14 de jan. 2011, às 13 horas e 45 minutos.

${ }^{19}$ PINTO, Francisco Eduardo. Cartas de sesmarias de Minas Gerais: como localizar a documentação e compreender a transformação do texto do documento ao longo do século XVIII. In: MONTEIRO, Rodrigo Bentes (org.). Espelhos deformantes: fontes, problemas e pesquisas em História Moderna. São Paulo: Alameda, 2008, p. 251.

${ }^{20}$ Arquivo da Casa Setecentista. Livro de Registro de Sesmarias. 1.o Ofício. Códice 01, doc. 29, fl. 02.

${ }^{21}$ Arquivo da Casa Setecentista. Livro de Registro de Sesmarias. 1.o Ofício. Códice 01, doc. 29, fl. 03

${ }^{22}$ Arquivo da Casa Setecentista. Livro de Registro de Sesmarias. 1.o Ofício. Códice 01, doc. 29, fl. 08. 
do Rio Pomba. Esses primeiros moradores enviaram uma solicitação ao governador da Capitania para que fossem respeitados os direitos de posse antiga. Esse documento fazia referência àqueles que acompanharam o padre Manoel de Jesus Maria nos primeiros anos do estabelecimento do aldeamento de São Manoel de Rio Pomba, colocando em risco suas vidas para abrir caminhos até a capital (Ouro Preto), obra essa que foi de utilidade tanto para a catequese dos índios quanto para o aumento da população na nova freguesia. ${ }^{23}$ No referido documento faz-se referência ao fato de que

[...] os ricos e poderosos costumam tirar as terras dos pobres e humildes, com o seu respeito, porque a pobreza sempre foi desprezada, aborrecida e desatendida, e outras vezes alcançam cartas de sesmarias subornando a verdade e com elas colhem o trabalho dos pobres e thes chamam suas ${ }^{24}$

Essa queixa fazia referência aos custos de legalização das terras, pois como salientam, o pagamento de Juiz, escrivão e medidores inviabilizava a legitimação da terra mesmo quando trabalhada, e a impossibilidade de arcarem com esses custos os obrigava a deixá-la. ${ }^{25}$ Os requerentes solicitavam que o despacho de 02 de maio de 1768 - feito pelo então governador Luís Diogo Lobo da Silva, que proibia a concessão de sesmarias nas terras daqueles que estivessem, de uma forma ou de outra, associados à civilização dos indígenas ${ }^{26}$ - fosse respeitado e que não doassem sesmarias e nem mesmo permitissem a posse e a posterior concessão de títulos de sesmeiros àqueles que estivessem adentrando os limites das terras habitadas pelos requerentes. Assinaram o referido documento as seguintes pessoas: Silvestre Rodrigues, José Vieira Ferrete, Manoel de Mello, José da Silva, Manoel da Silva, Bartolomeu Lopes Garcia, Manoel Durões, José Chysostomo, Francisco de Barros e Valentim Dias. ${ }^{27}$

Alguns dos requerentes aparecem em outro documento, datado de 1768, no qual o padre Manoel de Jesus Maria destaca os nomes de Manoel Durões, Bartolomeu Lopes de Garcia, Valentim Dias, José Pereira Mosso, Francisco de Barros, Manoel de Mello, José da Silva, Manoel da Silva, José Vieira Ferrete e Silvestre Rodrigues, como moradores da região,

\footnotetext{
${ }^{23}$ AHU-MG. A790/06/02. C.x 134, doc. 49. Requerimento dos possuidores de terras dentro dos limites da nova freguesia do Mártir São Manuel do Rio da Pomba, solicitando confirmação de um despacho de 2 de maio de 1768, para não desfazer das suas sesmarias (terras concedidas aos povos), fl. 03.

${ }^{24}$ AHU-MG. A790/06/02. C.x 134, doc. 49. Requerimento dos possuidores de terras dentro dos limites da nova freguesia do Mártir São Manuel do Rio da Pomba, solicitando confirmação de um despacho de 2 de maio de 1768, para não desfazer das suas sesmarias (terras concedidas aos povos), fl. 03.

${ }^{25}$ AHU-MG. A790/06/02. C.x 134, doc. 49. Requerimento dos possuidores de terras dentro dos limites da nova freguesia do Mártir São Manuel do Rio da Pomba, solicitando confirmação de um despacho de 2 de maio de 1768, para não desfazer das suas sesmarias (terras concedidas aos povos), fl. 04.

${ }^{26}$ AHU-MG. A790/06/02. Cx. 134, doc. 49. Requerimento dos possuidores de terras dentro dos limites da nova freguesia do Mártir São Manuel do Rio da Pomba, solicitando confirmação de um despacho de 2 de maio de 1768, para não desfazer das suas sesmarias ( terras concedidas aos povos), fl. 04.

${ }^{27}$ AHU-MG. A790/06/02. Cx. 134, doc. 49. Requerimento dos possuidores de terras dentro dos limites da nova freguesia do Mártir São Manuel do Rio da Pomba, solicitando confirmação de um despacho de 2 de maio de 1768, para não desfazer das suas sesmarias ( terras concedidas aos povos), fl. 05.
} 
porém desprovidos de recursos. ${ }^{28}$ Com a exceção de José Pereira Mosso, todos os demais mencionados pelo padre Manoel de Jesus Maria assinaram o requerimento anteriormente tratado. Muitos dos requerentes de fato já habitavam a região há bastante tempo, como foi o caso de Valentim Dias - que aparece como padrinho nos registros de batismos de Ignácio, adulto, filho da índia catecúmena Antônia, de nação Coropó, em 1.o de dezembro de $1768^{29}$ e de Francisco de Barros, que também aparece na condição de padrinho do inocente Pedro (de nação Coropó), em 30 de junho de $1769 .^{30}$ Além de atuar como padrinho, Antônio, filho do casal Valentim Dias e Josepha Ferreira da Conceição, foi batizado em 7 de maio de 1769. No livro de registro de batismos, o casal aparece como "moradores na roça de Antônio Dias Ribeiro". ${ }^{31}$ Na mesma situação encontra-se Manoel Durões, que aparece na condição de padrinho de Tereza (índia adulta de nação Coropó) em 5 de dezembro de $1769 .^{32}$

A documentação acima indica que os primeiros a acompanharem o padre Manoel de Jesus Maria eram, em sua maioria, pessoas desprovidas de posses e procuravam, ao se estabelecer em uma área de fronteira aberta, melhorar sua condição social. As ações que perpetraram na região, como a participação nos batizados dos indígenas e o auxílio na abertura de caminhos, indicam que esperavam uma retribuição em troca. O padre Manoel de Jesus Maria frisou em petição feita ao governador Luís Diogo Lobo essa necessidade, quando afirmou que "[...] os homens que podem concorrer e já trabalharam na feitura do dito caminho [...] não se anima sem remuneração, pois são pobres". ${ }^{33}$ A pobreza a que se referia o padre era a incapacidade de pagar pela regularização das terras em que habitavam. Em outros termos, viviam de maneira irregular naquelas terras e esperavam que o Governador das Minas levasse em consideração os serviços prestados como forma de garantia de permanência nas mesmas terras.

\section{OS CONFLITOS AGRÁRIOS NA ÁREA CENTRAL DA MATA MINEIRA}

Foi nesse contexto que surgiu o primeiro conflito em torno da terra na área Central da Zona da Mata. Os irmãos Francisco e Manoel Pires Farinho solicitaram que os sesmeiros que confinam com eles não invadissem suas terras e acusaram João de Miranda de invadilas. ${ }^{34}$ A acusação de Francisco Pires Farinho foi grave, já que por ela João de Miranda era responsável tanto por invadir as terras do diretor quanto as terras indígenas. Francisco Pires Farinho não acusou diretamente João de Miranda, mas insinuou que desde a administração de Luís Diogo Lobo "[...] costumava mandar pôr em cartas de sesmarias que concedia, sendo

\footnotetext{
${ }^{28}$ APM. SC. 103. Registro de termos, petições e despachos (1752-1771), rolo22 - Gav. G- 03, fl. 53.

${ }^{29}$ Arquivo Eclesiástico da Paróquia de São Manoel de Rio Pomba. Livro de Registro de Batismo no 1, fl. 04.

${ }^{30}$ Arquivo Eclesiástico da Paróquia de São Manoel de Rio Pomba. Livro de Registro de Batismo no 1, fl. 05.

${ }^{31}$ Arquivo Eclesiástico da Paróquia de São Manoel de Rio Pomba. Livro de Registro de Batismo no 1, fl. 04.

${ }^{32}$ Arquivo Eclesiástico da Paróquia de São Manoel de Rio Pomba. Livro de Registro de Batismo no 1, fl. 05.

${ }^{33}$ APM. SC. 103. Registro de termos, petições e despachos (1752-1771), rolo22 - Gav. G - 03, fl. 53.

${ }^{34}$ AHU-MG. A782/12/11. Cx. 118, doc. 96. Requerimento do Capitão Francisco Pires Farinho e de seu irmão Manoel Pires Farinho, diretores dos índios cropós e croatos, da freguesia do Mártir São Manoel dos rios da Pomba e do Peixe, pedindo para que os sesmeiros que confinam com eles não ocupem as suas sesmarias, $\mathrm{fl}$. 04.
} 
para a vizinhança da Freguesia dos Índios, sem prejuízo dos novos estabelecimentos dos índios e dos empregados na redução deles". ${ }^{35}$

Como o diretor Francisco Pires Farinho havia anteriormente mencionado o nome de João de Miranda, ele deu a entender que este havia invadido as suas sesmarias e as terras indígenas. A base argumentativa de Farinho apoiou-se em suas ações em prol da Coroa. No requerimento em questão, o Diretor dos índios salienta que

[...] tem tido grande trabalho com os índios gentios, ainda antes de serem deles seus Diretores, se animaram com grande risco de vida, no tempo em que os ditos índios assolavam tudo, destruindo e matando, se introduzirem com eles para os reduzir a paz, sendo eles os primeiros que acompanharam o vigário Manoel de Jesus Maria. ${ }^{36}$

O sacrifício da própria vida ao penetrar nos sertões povoados de índios bravos e selvagens era um argumento comum dos sertanistas que pretendiam alcançar alguma mercê régia. ${ }^{37}$ Nesse caso em questão, Francisco Pires Farinho frisou seu importante papel em relação à pacificação dos indígenas para solicitar a devolução de terras que ele entendia serem suas e que João de Miranda havia tomado inescrupulosamente. No mesmo documento, Farinho destaca que o sucesso de seu trabalho com os índios possibilitou a chegada de novos habitantes à região, mas que houve

[...] pessoas de tão pouca consideração e má consciência que se atreveram a pedir sesmarias não só sobre as terras dos índios da dita situação, mas ainda em prejuízo dos suplentes, fingindo que não pretendiam prejudicar ou entrar para as terras dos suplentes. ${ }^{38}$

Francisco Pires Farinho, visando reforçar a argumentação simbólica, anexou, em um instrumento público, cartas que confirmavam a sua atuação em prol dos índios. As referidas cartas não nos auxiliam no entendimento do conflito, pois sequer fazem menção a João de Miranda Silva ou a alguma invasão perpetrada por ele em terras de Francisco Pires Farinho. Elas visam reforçar a importância da atuação de Francisco Farinho nos sertões do rio Pomba, mostrando, com isso, que o dito diretor era um vassalo fiel da Coroa.

\footnotetext{
${ }^{35}$ AHU-MG. A782/12/11. Cx. 118, doc. 96. Requerimento do Capitão Francisco Pires Farinho e de seu irmão Manoel Pires Farinho, diretores dos índios cropós e croatos, da Freguesia do Mártir São Manoel dos rios da Pomba e do Peixe, pedindo para que os sesmeiros que confinam com eles não ocupem as suas sesmarias, fl. 03.

${ }^{36}$ AHU-MG. A782/12/11. Cx. 118, doc. 96. Requerimento do Capitão Francisco Pires Farinho e de seu irmão Manoel Pires Farinho, diretores dos índios cropós e croatos, da Freguesia do Mártir São Manoel dos rios da Pomba e do Peixe, pedindo para que os sesmeiros que confinam com eles não ocupem as suas sesmarias, fl. 02.

${ }^{37}$ A respeito dos procedimentos de autovalorização expressos nas solicitações de mercês e títulos, cf. ANDRADE, Francisco Eduardo. A invenção das Minas Gerais: empresas, descobrimentos e entradas nos sertões do ouro da América portuguesa. Belo Horizonte: Autêntica; EDPUC-MG, 2008.

${ }^{38}$ AHU-MG. A782/12/11. Cx. 118, doc. 96. Requerimento do Capitão Francisco Pires Farinho e de seu irmão Manoel Pires Farinho, diretores dos índios cropós e croatos, da Freguesia do Mártir São Manoel dos rios da Pomba e do Peixe, pedindo para que os sesmeiros que confinam com eles não ocupem as suas sesmarias, fl. 02-03.
} 
João de Miranda Silva confirmou o seu título de sesmeiro em 16 de outubro de $1775^{39}$, portanto depois da reclamação feita pelos irmãos Farinho. Sua solicitação de sesmarias ocorreu aproximadamente um ano antes, em oito de agosto de $1774 .{ }^{40}$ É interessante assinalar que no documento em questão faz-se referência à reclamação feita por Francisco Pires Farinho, mas João de Miranda Silva também ressalva que o mesmo Farinho depôs a favor do suplente "como consta da certidão junta". ${ }^{41}$ No mesmo documento, João de Miranda Silva acusa Francisco Pires Farinho de querer se apossar de suas terras, quando afirma que "verificando-se o dolo e a malícia do dito Francisco querendo este assenhorear-se das ditas terras dizendo uma vez que lhe pertence, e outras que as quer distribuir aos índios, ao mesmo tempo [...]". ${ }^{42}$ João de Miranda Silva ainda alega que já havia feito despesas com as referidas sesmarias adquiridas, indicando que já estava de posse das terras e que pretendia apenas obtê-las legalmente. Entre as despesas, João de Miranda destacou que nas terras já havia plantado e inclusive pago o dízimo, "e feito várias benfeitorias estando atualmente morando nas ditas terras com toda a sua fábrica e escravatura". ${ }^{43}$

Empreender todas as etapas (solicitação de carta de sesmaria, solicitação de confirmação, medição e demarcação) levava tempo e possuía um custo que nem todos podiam arcar. Aqueles que podiam, pretendiam não somente ter suas terras legalizadas frente à Coroa, mas também garantir-se legalmente diante de possíveis conflitos agrários. É dentro dessa lógica que devemos entender a ação de João de Miranda Silva. Contra os argumentos e o poder simbólico de Diretor dos Índios de Francisco Pires Farinho, João de Miranda Silva contrapôs a legalidade de suas terras, solicitadas, medidas e demarcadas, a sua produtividade (outro quesito importante da Lei de Sesmarias), além do cumprimento fiscal (pagamento dos dízimos referentes à produção agrária). O conflito, nesse caso, sai do plano meramente simbólico e entra no plano jurídico, pautado por argumentos mais sólidos como a produtividade agrária e o pagamento dos dízimos.

Desse modo, as duas partes se acusaram de tentativa de invasão de terras. Francisco Pires Farinho claramente usou da condição de Diretor dos Índios e dos direitos que esse cargo the garantia para defender-se e ao mesmo tempo acusar João de Miranda Silva. Este, por seu turno, afirmava que a posse de sua sesmaria era justa e pacífica, uma vez que as acusações perpetradas por Farinho eram classificadas como caluniosas. A carta de sesmaria é um documento jurídico que indica a ação da Coroa em um dos três pilares de sustentação do poder régio, a saber: a Justiça. Em outros termos, configurara-se como uma tentativa da Coroa de submeter a doação de terras à sua determinação, garantindo, ou tentando garantir, a harmonia nas relações entre os súditos. ${ }^{44}$ Tudo indica que João de

\footnotetext{
${ }^{39}$ Arquivo da Casa Setecentista. Livro de Registro de Sesmarias. 1.o Ofício. Códice 05, doc. 221, fl. 01.

${ }^{40}$ APM Secretaria de Governo da Capitania. SC 206. Registro de sesmarias (com índice no início). Rolo 43, Gav. G-3, fl. 12.

${ }^{41}$ Arquivo da Casa Setecentista. Livro de Registro de Sesmarias. 1. Ofício. Códice 05, doc. 221, fl. 03.

${ }^{42}$ Arquivo da Casa Setecentista. Livro de Registro de Sesmarias. 1.o Ofício. Códice 05, doc. 221, fl. 03.

${ }^{43}$ Arquivo da Casa Setecentista. Livro de Registro de Sesmarias. 1.o Ofício. Códice 05, doc. 221, fl. 03.

${ }^{44}$ MOTTA, Márcia Maria Menendes. Op. cit., p. 131.
} 
Miranda Silva obteve a posse legal das terras contestadas por Francisco Pires Farinho, pois como o documento apresentado por Silva é posterior à reclamação feita por Farinho e como aquele era um documento que terminava confirmando a posse de João de Miranda Silva, ao afirmar que "nada se opuseram às ditas posses judicialmente" ${ }^{45}$, podemos concluir que a reclamação do Diretor dos Índios não foi atendida pelas autoridades coloniais.

Outro conflito que também envolveu a solicitação de demarcação e medição de sesmaria foi protagonizado por Domingos Silva Guimarães. Ele se encontrava na região desde muito cedo, conforme podemos perceber pela análise do Livro de Registros de Batismos da Igreja de São Manoel, em rio Pomba. Um desses registros, datado de 22 de julho de 1770, traz uma informação interessante, pois o padrinho do índio Antônio (filho de catecúmenos) foi Marcos Lopes de São Payo, que no registro é mencionado como "morador na casa de Domingos da Silva Guimarães no Xopotó" . ${ }^{46}$ Em outro momento (26 de dezembro de 1770), sua mulher Antônia Leite Pereira aparece na condição de madrinha do índio adulto Estevão, cacique dos coropós, de Luiz, filho do dito cacique, de Ignácia (índia adulta). ${ }^{47}$

Em 27 de dezembro do mesmo ano, sua esposa participou ainda dos batismos de Maria (índia adulta coropó), Narciso (índio adulto coropó), Luiza (índia adulta coropó) e de Marcelino (índio adulto coropó). ${ }^{48}$ Encontramos ainda a presença de outra pessoa em sua casa, a saber, Maria da Silva Guimarães, que aparece como madrinha do índio João, em 27 de dezembro de $1770 .{ }^{49}$ Apesar de morador antigo na região, conforme indicam os registros de batismos acima assinalados, Domingos da Silva Guimarães viu-se envolvido também em conflitos em torno da posse de terras com Geraldo Gomes de Campos, em 1774. As terras de sesmarias pertencentes a Domingos da Silva Guimarães foram obtidas por meio de compra. 0 vendedor foi o reverendo Bernardino José da Rocha. ${ }^{50}$ Domingos da Silva Guimarães solicitou uma remedição das terras de sesmarias, em função dos conflitos (algumas dúvidas como diz o documento) que vivenciava com outros sesmeiros, em especial com Geraldo Gomes de Campos. ${ }^{51}$ Contudo, essa remedição, depois de efetuada, acabou por gerar mais reclamações, uma vez que Geraldo Gomes de Campos alegou ter sido prejudicado, já que pela nova medição uma parte de suas terras ficou nas mãos de Domingos da Silva Guimarães. Esse caso configura uma das formas típicas de acesso a terra na Capitania de Minas Gerais, a compra e venda de sesmarias. Se em outras capitanias isso também ocorria $^{52}$, em Minas esse processo era mais frequente. Segundo Ângelo Alves Carrara, a "rapidez como a propriedade trocou de mãos, que as próprias concessões nos informam, tornaram as sesmarias instrumentos menores de acesso a terra"; contudo, o mesmo autor ainda destacou que a procura pelo título de sesmaria justificava-se como uma forma de

\footnotetext{
${ }^{45}$ Arquivo da Casa Setecentista. Livro de Registro de Sesmarias. 1. Ofício. Códice 05, doc. 221, fl. 09.

${ }^{46}$ Arquivo Eclesiástico da Paróquia de São Manoel de Rio Pomba. Livro de Registro de Batismos n.o 1, fl. 07.

${ }^{47}$ Arquivo Eclesiástico da Paróquia de São Manoel de Rio Pomba. Livro de Registro de Batismos n.o 1, fl. 09.

${ }^{48}$ Arquivo Eclesiástico da Paróquia de São Manoel de Rio Pomba. Livro de Registro de Batismos n.o 1, fl. $10-11$.

${ }^{49}$ Arquivo Eclesiástico da Paróquia de São Manoel de Rio Pomba. Livro de Registro de Batismos n.o 1, fl. 09.

${ }^{50}$ Arquivo da Casa Setecentista. Livro de Registro de Sesmarias. 1.e Ofício. Códice 07, doc. 294, fl. 02.

${ }^{51}$ Arquivo da Casa Setecentista. Livro de Registro de Sesmarias. 1.o Ofício. Códice 07, doc. 294, fl. 03.

${ }^{52}$ Sobre a possibilidade da compra e venda de sesmarias na região Nordeste, cf. FERLINE, Vera Lúcia Amaral. Terra, trabalho e poder: o mundo dos engenhos no Nordeste colonial. Bauru: EDUSC, 2003
} 
"garantia a posses já alcançadas ou a terras já compradas". ${ }^{53}$ A situação de Domingos da Silva Guimarães é parecida, já que ele procurou legalizar por meio do título de sesmarias suas terras compradas ao reverendo Bernardino José da Rocha; contudo, isso não impediu que o conflito ocorresse. A procura pela titulação de sesmarias era importante não somente como garantia legal da posse, mas também como forma de mediar possíveis conflitos, uma vez que coloca como mediador a autoridade colonial representada pelo Juiz de Sesmarias.

As terras de Geraldo Gomes de Campos confrontavam pela frente com as terras de João Manoel de Medeiros, com as do Capitão Manoel da Silva Couto, ${ }^{54} \mathrm{com}$ as de Antônio João Belay e com as do Alferes José Alves Maciel. Alguns desses nomes são mencionados como moradores antigos na Freguesia de São Manoel de Rio Pomba. O Capitão Manoel da Silva Couto em seu pedido de sesmarias afirmou "que se achava com bastantes escravos e não possuía terras nenhuma com que possa plantar [...]". Suas sesmarias, que confrontavam com as de Thomas Rodrigues da Cunha e de João de Novais ${ }^{55}$, foram concedidas pelo governador interino José Freire de Andrade, em 11 de agosto de $1758 .^{56}$ Alferes José Alves Maciel e sua mulher Vivência Maria de Oliveira são relacionados como padrinhos no início da década de $1770 .^{57}$ Suas sesmarias foram obtidas em 1758 "por arrematação que fizera em hasta pública o qual sítio fora do Alferes Antônio Dias" e que confrontava com as terras do guarda-mor Alexandre da Cunha. ${ }^{58} \mathrm{~A}$ intenção de José Alves Maciel era regularizar as terras que havia comprado mediante a obtenção de título de sesmaria, ou seja, um procedimento semelhante ao praticado por Domingos da Silva Guimarães.

Antônio João Belay aparece no livro de registro de batismos da Freguesia de São Manoel do Rio Pomba como morador em Guarapiranga. ${ }^{59}$ Apesar dessa referência, Antônio João Belay também aparece como sesmeiro vizinho às terras de Manoel de Jesus Maria, situadas no Xopotó e obtidas em 1758, situada na dita carta de sesmaria como pertencente ao Termo da Vila de São José. ${ }^{60}$ Eram, portanto, pessoas que já estavam na região desde antes do início da formação do aldeamento de São Manoel às margens do rio Pomba. Geraldo Gomes de Campos tentou impedir a medição das terras, alegando que o pedido de Domingos da Silva Guimarães envolvia a medição de três quartos de suas terras "e que fique o outro quarto para medir com os que confronta com terras do suplente [Geraldo Gomes de

\footnotetext{
${ }^{53}$ CARRARA, Ângelo Alves. Contribuição para a história agrária de Minas Gerais - séculos XVIII-XIX. Mariana: UFOP, 1999, p. 11-13.

${ }^{54}$ Manoel de Silva Couto obteve suas sesmarias no Xopotó em 1758. Cf. APM. Secretaria de Governo da Capitania. SC 119. Registro de sesmarias (com índice no final). Rolo 26, Gav. G-3, fl. 176-177.

${ }^{55}$ APM. Secretaria de Governo da Capitania. SC 119. Registro de sesmarias (com índice no final). Rolo 26, Gav. G-3, fl. 176.

${ }^{56}$ APM. Secretaria de Governo da Capitania. SC 119. Registro de sesmarias (com índice no final). Rolo 26, Gav. G-3, fl. 177.

${ }^{57}$ Arquivo Eclesiástico da Paróquia de São Manoel de Rio Pomba. Livro de Registro de Batismos n. 1, fl.

${ }^{58}$ APM. Secretaria de Governo da Capitania. SC 119. Registro de sesmarias (com índice no final). Rolo 26, Gav. G-3, fl. 44.

${ }^{59}$ Arquivo Eclesiástico da Paróquia de São Manoel de Rio Pomba. Livro de Registro de Batismos n.o 1, fl

${ }^{60}$ APM. Secretaria de Governo da Capitania. SC 119. Registro de sesmarias (com índice no final). Rolo 26, Gav. G-3, fl. 42.
} 
Campos]". ${ }^{61}$ Domingos da Silva Guimarães, por sua vez, também procurou embargar os requerimentos enviados por Geraldo Gomes de Campos, alegando que este pretendia embargar a posse do suplente [Domingos da Silva Guimarães]. ${ }^{62}$ Domingos da Silva Guimarães alegou ainda que a intenção de Geraldo Gomes de Campos era se apossar de suas terras e para isso enviava, por seus procuradores, requerimento tentando impedir que tomasse a justa posse de suas sesmarias. ${ }^{63}$ Geraldo Gomes de Campos, ao longo da disputa, fez uso de vários procuradores, entre eles o Capitão Manoel da Silva Couto, João Manoel de Medeiros, sesmeiros que confrontavam com ele.

Um dos argumentos utilizados pelo procurador de Geraldo Gomes Campos para impedir a remedição das terras foi a antiguidade da posse do suplente frente ao precoce domínio das terras de Domingos da Silva Guimarães. O documento em questão ressalta que as sesmarias foram confirmadas em 1758 , não assinalando a data em que foram obtidas. ${ }^{64} \mathrm{~A}$ antiguidade era um argumento relevante e o procurador, no mesmo documento, destaca que "sendo esta mais antiga que a do dito Guimarães, e por isso não deveria entrar pelas mesmas, que como primeira tem preferência a outra qualquer que fosse alcançada em segundo lugar [...]" ${ }^{65}$ Como mostramos acima, muitos desses sesmeiros, incluindo Geraldo Gomes de Campos e seus procuradores, tinham obtido suas sesmarias ainda na década de 1750 e mostraram-se preocupados com a proposta de remedição de Domingos da Silva Guimarães, pois tal ação poderia resultar em perdas para eles. Era relativamente comum que os sesmeiros não respeitassem os limites demarcados de suas sesmarias. Eduardo Pinto frisou que "se, no papel, estavam fixadas as medidas, na prática, as extensões dominadas pelos sesmeiros poderiam alcançar a distância que seu poder de dominação sobre os outros colonos permitisse". ${ }^{66}$ Logo, era natural que se mostrassem perturbados pela chegada de um novo sesmeiro e pela proposta de remarcação e remedição de suas terras, fato que poderia gerar, como de fato gerou, conflito com os sesmeiros mais antigos.

A preocupação dos sesmeiros antigos da área pode ser percebida não somente pelo fato de terem atuado como procuradores de Geraldo Gomes de Campos, mas pelas ações mesmas que moveram contra Domingos da Silva Guimarães. Um dos procuradores de Geraldo Gomes de Campos e sesmeiro antigo no Xopotó, João Manoel de Medeiros, também reclamou da remedição proposta por Domingos da Silva Guimarães. ${ }^{67}$ A dita preocupação, como ressaltado acima, baseava-se na possibilidade de que a remedição das terras indicasse que os sesmeiros haviam incluído mais terras do que o título de sesmarias deles Ihes garantia. Foi justamente o que ocorreu; a disputa judicial deu ganho de causa a

\footnotetext{
${ }^{61}$ Arquivo da Casa Setecentista. Livro de Registro de Sesmarias. 1. Ofício. Códice 07, doc. 294, fl. 11.

${ }^{62}$ Arquivo da Casa Setecentista. Livro de Registro de Sesmarias. 1. Ofício. Códice 07, doc. 294, fl. 17.

${ }^{63}$ Arquivo da Casa Setecentista. Livro de Registro de Sesmarias. 1.9 Ofício. Códice 07, doc. 294, fl. 17.

${ }^{64}$ Arquivo da Casa Setecentista. Livro de Registro de Sesmarias. 1. Ofício. Códice 07, doc. 294, fl. 32.

${ }^{65}$ Arquivo da Casa Setecentista. Livro de Registro de Sesmarias. 1.e Ofício. Códice 07, doc. 294, fl. 32.

${ }^{66}$ PINTO, Francisco Eduardo. Cartas de sesmarias de Minas Gerais: como localizar a documentação e compreender a transformação do texto do documento ao longo do século XVIII. In: MONTEIRO, Rodrigo Bentes (org.). Op. cit., p. 258

${ }^{67}$ Arquivo da Casa Setecentista. Livro de Registro de Sesmarias. 1. Ofício. Códice 07, doc. 294, fl. 36.
} 
Domingos da Silva Guimarães, baseado no fato de que a remedição, após ser concluída, realmente tirou de Geraldo Gomes de Campos

[...] alguma porção de terra que ocupasse além da que se lhe concedeu por sesmaria, se the não fazia agravo pelo não poder possuir sem o título de sesmaria e a dever restituir logo não mostrando in continenti, e ser privado dela, porque nos bens da Coroa não basta a posse sem título [...]. ${ }^{68}$

O mesmo documento conclui que "sendo os bens da Coroa em sua origem, e depois da Ordem, não os podem possuir, sem mostrar título por que conste conceder-lhos a Coroa". ${ }^{69}$ Essa conclusão acabou por transformar a acusação de Geraldo Gomes de Campos em uma causa injusta, pois não encontrava base na legislação coeva, já que o autor da acusação não estava dentro da lei. ${ }^{70}$ É interessante notar que, ao contrário do conflito anteriormente analisado (entre Francisco Pires Farinho e João de Miranda Silva), este se pautou pela constante busca de respaldo jurídico legal e não pela apresentação de argumentos baseados em poder simbólico, como procedeu Francisco Farinho.

A disputa entre Geraldo Gomes de Campos e Domingos da Silva Guimarães expôs aspectos relevantes da sociedade colonial e da administração da justiça nessa sociedade. Em primeiro lugar, indicou o quão significativo era, para a Coroa, a regularização das terras em sesmarias. Geraldo Gomes de Campos perdeu a disputa justamente em função de não possuir título de sesmarias de uma parte de suas terras que, na remedição solicitada por Domingos da Silva Guimarães, reclamou ter perdido. Em segundo lugar, revelou o papel de mediador do aparelho administrativo colonial no tocante aos conflitos em torno da terra. Se a Coroa pretendia mostrar sua força em relação àqueles que ainda não haviam obtido título de sesmarias, mas mesmo assim produziam, por intermédio da regularização das terras, esse poder também apareceu por meio da mediação de conflito entre sesmeiros, ou seja, entre aqueles que haviam obtido o título de sesmaria.

\section{PRODUÇÃO AGRÁRIA E CONFLITO}

É relevante salientar que os conflitos em torno da questão agrária também gravitavam ao redor da produção agrária, uma vez que esta era utilizada como uma forma de mostrar a antiguidade da posse. Esse aspecto ficou patente no último conflito analisado, uma vez que um dos argumentos centrais para garantir a proibição da remarcação das terras foi justamente o fato de que Geraldo Gomes de Campos já as possuía há muito tempo e já produzia nelas. ${ }^{71}$ Este argumento, entretanto, não foi suficiente para dar ganho de causa a Geraldo Gomes de Campos, uma vez que o processo, conforme mostrado acima, concluiu que ele havia anexado terras que não estavam dentro dos limites de doação de sua carta de sesmarias. De qualquer forma, a presença da argumentação indica-nos uma preocupação

\footnotetext{
${ }^{68}$ Arquivo da Casa Setecentista. Livro de Registro de Sesmarias. 1.o Ofício. Códice 07, doc. 294, fl. 41.

${ }^{69}$ Arquivo da Casa Setecentista. Livro de Registro de Sesmarias. 1.o Ofício. Códice 07, doc. 294, fl. 41.

${ }^{70}$ Arquivo da Casa Setecentista. Livro de Registro de Sesmarias. 1.e Ofício. Códice 07, doc. 294, fl. 42.

${ }^{71}$ Arquivo da Casa Setecentista. Livro de Registro de Sesmarias. 1.e Ofício. Códice 07, doc. 294, fl. 32.
} 
com a produção agrária, tanto da parte do colono quanto da parte da administração colonial, caso contrário o argumento não teria sido realçado nos autos.

A presença da produção agrária na área Central da Mata pode ser averiguada pela solicitação de sesmarias feita por Felisberto Antônio Leal; o solicitante afirmou possuir bastante escravo, mas não ser possuidor de terras e que sabia haver "nas cabeceiras do Ribeirão de Ubá, freguesia do Mártir São Manoel do Rio Pomba, se achar matos virgens [...] sem concessão alguma". ${ }^{72}$ Felisberto Antônio Leal, em seu pedido, utilizou as palavras certas para reivindicar terras: ser possuidor de escravos. Tal fato implicava em poder tornar as terras agricultáveis, fato que geraria dízimos para a Coroa.

Em outra solicitação, José da Silva de Andrade, morador na Borda do Campo (atual Barbacena), ganhou uma carta de sesmaria de meia légua no sertão do rio Pomba do governador das Minas, D. Rodrigo José de Meneses (1780-1783), e depois solicitou a sua confirmação à rainha D. Maria I. Na carta apresentada para solicitar a confirmação, destacou-se a afirmação de que o solicitante vivia da agricultura, mas não possuía terras para cultivar e que nos ditos sertões havia terras devolutas entre as sesmarias de Francisco Luis, Francisco José dos Santos e Pedro de Oliveira Santos. ${ }^{73}$ O caso de José da Silva de Andrade nos faz refletir a respeito dos critérios de solicitação de sesmarias, pois ao argumentar que vivia da agricultura o solicitante dava a entender que plantava, mas concomitantemente, em seu pedido, ele diz que não possuía terras para plantar. A contradição em termo de sua solicitação indica-nos que José da Silva de Andrade já plantava na área em que solicitou as sesmarias e pretendia certamente regulamentar sua posse.

A produção agrária sobre a qual incidiam os dízimos era diversificada. Não há indícios de que uma determinada cultura tenha se sobreposto às demais. Tal característica marca a agricultura de áreas como a Central da Mata de Minas neste período. Sua produção agrária voltava-se para o autoabastecimento, o que não impedia que parte dessa produção estivesse voltada para as trocas mercantis.

Em relação à produção para o autoabastecimento, podemos destacar a solicitação feita pelo padre Manoel de Jesus Maria de isenção do pagamento dos dízimos ao contratador Alexandre Pereira de Araújo, que arrematou pelo valor de dois contos e cinquenta e um mil réis. ${ }^{74}$ Seu pedido foi atendido, com a ressalva de que caso vendesse algum dos produtos que plantava e criava seria obrigado a pagar o tributo. ${ }^{75}$ Esse documento é interessante, pois auxilia-nos a entender o funcionamento sócio-econômico da agricultura local. O padre Manoel de Jesus Maria afirma que comprou escravos para que

\footnotetext{
72 APM. Casa dos Contos. Cx. 101, doc. 20493, rolo 531 A. Requerimento de Felisberto Antônio Leal sobre a concessão de sesmaria no Ribeirão de Ubá, Freguesia do Mártir São Miguel do Rio Pomba.

${ }^{73}$ AHU-MG. Cx. 123, doc. 24. Requerimento de José da Silva de Andrade, solicitando à D. Maria I a mercê de lhe confirmar a doação, em sesmaria, de meia légua de terra em quadra no sertão do Rio da Pomba, fl. 03.

${ }^{74}$ AHU-MG. A805/03/14. Cx. 175, doc. 09. Requerimento do padre Manoel de Jesus Maria, vigário colado na Freguesia do Mártir São Manoel dos sertões dos rios da Pomba e Peixe dos índios croatos, solicitando a mercê de lhe isentar do pagamento de dízimos pelas suas plantações e criações, fl. 08.

${ }^{75}$ AHU-MG. A805/03/14. Cx. 175, doc. 09. Requerimento do padre Manoel de Jesus Maria, vigário colado na Freguesia do Mártir São Manoel dos sertões dos rios da Pomba e Peixe dos índios croatos, solicitando a mercê de lhe isentar do pagamento de dízimos pelas suas plantações e criações, fl. 03.
} 
trabalhassem em suas terras na qual plantava feijão para seu sustento e dos índios que catequizava. ${ }^{76}$ A referência ao feijão nesse documento é relevante, pois indica-nos que esse produto não era normalmente plantado para o mercado, mas para o consumo próprio. Em carta enviada ao Governador das Minas, Luiz da Cunha Meneses, a respeito do desbaratamento de uma quadrilha de salteadores e datada de 10 de julho de 1784, o sargento-mor Pedro Affonso Galvão de São Martinho relatou a presença de roças de milho, feijão, banana, ervilhas, couve, alhos e cebolas nas proximidades do rio Paraibúna. ${ }^{77}$ Mesmo situando-se na área Sul da Mata de Minas, a referência do sargento-mor indica-nos que o feijão era entendido como alimento básico voltado, normalmente, para o autoconsumo e muito pouco para o mercado.

Apesar de o feijão aparecer com relativo destaque na documentação coeva, interessa-nos mais os produtos voltados para o mercado. Nesse sentido, a carta de 1799 do padre Manoel de Jesus Maria, na qual defendia o fim das doações de sesmarias em terras indígenas, nos forneceu mais elementos a respeito da produção agrária na freguesia ao afirmar existirem "trinta e dois engenhos de cana, outras plantações de tabaco, algodão, anil, café [...]" ${ }^{78}$ As informações do padre Manoel de Jesus Maria a respeito da existência de trinta e dois engenhos na Freguesia de São Manoel do Rio Pomba é bastante relevante para entendermos a produção agrária na área. O levantamento de engenhos estava proibido em Minas Gerais em função dos problemas causados pela cachaça, especialmente entre escravos e forros. ${ }^{79}$

Em outro documento, o padre Manoel de Jesus Maria confirma a existência de produção de cachaça dentro dos limites da Freguesia de São Manoel do Rio Pomba. Ao solicitar providências contra os alferes Eugênio José da Silva e João de Almeida Lima, por invasão e destruição de terras e plantações indígenas, o padre destaca que a intenção dos agressores é ocupar as terras indígenas para plantar cana e construir um engenho para produzir a referida bebida. ${ }^{80}$ As proibições relacionadas à construção de novos engenhos parecem não ter surtido efeito, pois se por um lado a cachaça exercia um efeito deletério sobre as pessoas, especialmente sobre os indígenas, e era alvo de preocupação da administração colonial, por outro, a possibilidade de aumentar a arrecadação dos dízimos por meio da produção em torno dos engenhos atuou de forma sedutora para com os

\footnotetext{
${ }^{76}$ AHU-MG. A805/03/14. Cx. 175, doc. 09. Requerimento do padre Manoel de Jesus Maria, vigário colado na freguesia do Mártir São Manoel dos sertões dos rios da Pomba e Peixe dos índios croatos, solicitando a mercê de lhe isentar do pagamento de dízimos pelas suas plantações e criações, fl. 06

77 APM. Casa dos Contos. Cx. 3 - 10072, rolo 501. Carta do sargento-mor, Pedro Afonso Galvão de São Martinho, ao [governador] Luiz da Cunha Menezes sobre ter encontrado a roça dos salteadores e outra roça com plantações de milho, feijão, banana, ervilhas, couve, alhos e cebolas.

${ }^{78}$ AHU-MG. 1799/27/08. Cx. 149, doc. 62. Carta de Manoel de Jesus Maria para D. Rodrigo de Souza Coutinho, expondo sobre o prejuízo para os índios na concessão de sesmarias pelo Governador das Minas, fl. 3.

${ }^{79}$ Cf. a lei em AHU-MG. 1770/12/07. Cx. 99, doc. 33. Carta de D. José Luís de Menezes, conde de Valadares e governador de Minas Gerais, para o conde de Oeiras, informando sobre providências que têm tomado para a observância da ordem de 12 de junho de 1743, referente à edificação e trasladação de engenhos de cana, fl. 03 ${ }^{80}$ APM. Casa dos Contos. Cx. 35, doc. 30054, rolo 511. Requerimento do Padre Manuel de Jesus Maria, Freguesia do Mártir São Manuel dos Sertões e Rio da Pomba e Peixe, sobre as providências com relação ao alferes Eugênio José da Silva e João de Almeida Lima pela invasão e incêndio nas terras indígenas e fabricação de cachaça para os índios, fl. 01-02.
} 
administradores da Capitania, conforme indica a carta de D. Antônio de Noronha ao Conselho Ultramarino. Na referida missiva, o Governador das Minas frisou:

[...] não tenho feito procedimento algum [...] porque demolindo-se os engenhos que se acham feitos posteriormente a sobredita ordem, se causaria um gravíssimo prejuízo aos moradores desta Capitania e uma considerável diminuição aos subsídios Voluntário e Literário. $^{81}$

Como a administração colonial nada fez para colocar em prática a proibição para se erguer engenhos na Capitania, eles se proliferaram em todas as regiões, e na área Central da Mata mineira não foi diferente. Analisando o inventário de Joaquim Gonçalves Ferreira, feito em 1791, encontramos além de onze escravos, a presença de "uma fazenda chamada São Bartolomeu com casas de vivenda, paiol, moinho coberto de telhas, engenhoca, senzala e uma sesmaria de terras de matos virgens e capoeiras". ${ }^{82}$ Sua escravaria era de idade avançada, sendo que de seus onze escravos, um (José Benguela) estava com 60 anos $^{83}$ e dois (Miguel Congo e Miguel Angola) estavam com 56 anos. ${ }^{84}$ Os demais se encontravam em idade útil, situando-se na casa dos 30 e 40 anos. ${ }^{85}$ Joaquim Gonçalves Ferreira, portanto, possuía oito escravos em condições boas de trabalho; tal fato o coloca acima da média dos senhores de escravos da primeira metade do século XIX na região, ou seja, como alguém possuidor de recursos financeiros. A presença de uma engenhoca é indicativa do fabrico de cachaça, produto utilizado como forma de pagamento pelo trabalho indígena na região.

Em 1802, Maria Ferreira da Anunciação Cabral e Câmara, moradora na Freguesia de Guarapiranga e Xopotó, solicitou autorização para erguer três engenhos de água para açúcar e aguardente em suas terras. ${ }^{86}$ Essa solicitação é interessante, pois ela foi feita muito após a proibição e após também as trocas de correspondências acima expostas. A aceitação pelas autoridades $^{87}$ para que Maria Ferreira da Anunciação Cabral Câmara estabelecesse três

\footnotetext{
${ }^{81}$ AHU-MG. 1777/01/07. Cx. 111, doc. 01. Carta de D. Antônio de Noronha, Governador das Minas, informando Martinho de Mello e Castro, dentre outros assuntos, sobre o pedido de socorro que lhe formulou o vice-rei do Brasil, assim como também da demolição de engenhos de açúcar e aguardente, fl. 03.

${ }^{82}$ Arquivo da Casa Setecentista. Inventário de Joaquim Gonçalves Ferreira (1791). Cx. 82, auto 1735, fl. 12.

${ }^{83}$ Arquivo da Casa Setecentista. Inventário de Joaquim Gonçalves Ferreira (1791). Cx. 82, auto 1735, fl. 10.

${ }^{84}$ Arquivo da Casa Setecentista. Inventário de Joaquim Gonçalves Ferreira (1791). 1.o ofício. Cx. 82, auto 1735, fl. 10 .

${ }^{85}$ Arquivo da Casa Setecentista. Inventário de Joaquim Gonçalves Ferreira (1791). 1.o ofício. Cx. 82, auto 1735, fl. 10-11.

${ }^{86}$ AHU-MG. 1802/09/06. Cx. 165, doc. 11. Carta do Governador Bernardo de Lorena para o Visconde de Anadia, sobre os requerimentos de João Antônio Rodrigues dos Santos e Maria Ferreira da Anunciação Cabral e Câmara. O primeiro pede nomeação no posto de Coronel do 4. Regimento de Cavalaria de Milícias de Ouro Preto e a segunda pede licença para erigir três engenhos de água para açúcar e aguardentes nas suas fazendas, fl. 04.

${ }^{87}$ AHU-MG. 1802/09/06. Cx. 165, doc. 11. Carta do Governador Bernardo de Lorena para o Visconde de Anadia, sobre os requerimentos de João Antônio Rodrigues dos Santos e Maria Ferreira da Anunciação Cabral e Câmara. O primeiro pede nomeação no posto de Coronel do 4. Regimento de Cavalaria de Milícias de Ouro Preto e a segunda pede licença para erigir três engenhos de água para açúcar e aguardentes nas suas fazendas, fl. 07 .
} 
engenhos em uma freguesia vizinha à de São Manoel ${ }^{88}$ é sintomático e nos leva a crer que a Freguesia de São Manoel do Rio Pomba também vivenciou o mesmo processo. Outro caso semelhante é o de Antônio Lopes de Moraes, que solicitou a confirmação de meia légua de sesmaria no ribeirão São Bento do Xopotó ${ }^{89}$, assim como o caso de João Andrade da Mota, que pediu a confirmação de terras na paragem do rio Xopotó, termo da cidade de Mariana. ${ }^{90}$ O fato de os suplicantes apresentarem-se como moradores da Freguesia de Piranga e Xopotó (Maria Ferreira da Anunciação Cabral Câmara), ou São Bento do Xopotó (Antônio Lopes de Morais), ou até mesmo referir-se apenas ao Termo a que pertence a paragem (como no caso do padre João Andrade da Mota), leva-nos a crer que ela residia ou na fronteira com a Freguesia de São Manoel do Rio Pomba (próxima ao mesmo rio), ou mesmo dentro da atual área Central da Zona da Mata, uma vez que o rio Xopotó nasce no atual município de São Geraldo e corta também a área Central da Mata, e muitos moradores da Freguesia de São Manoel eram moradores nas margens do mesmo rio.

Além da cachaça, o milho também era um produto comum na produção da área Central da Mata de Minas. A análise do testamento de Martinho Pires Farinho, irmão dos Diretores dos Índios, Manoel e Francisco Pires Farinho, indica a presença da produção desse produto. Suas sesmarias localizavam-se nas cabeceiras do rio Turvo e foram obtidas em 17 de agosto de $1786 .{ }^{91}$ Como sacerdote, Martinho atuou em batismos na referida região, conforme indicam os registros do Livro de Batismos da Igreja Matriz de São Manoel. Em seu testamento, declarou possuir "terras de plantar e minerar, uma fábrica de roda mineral aparelhada, uns gados, porcos, cavalos, ferramentas [...]". ${ }^{92}$ A roda mineral aparelhada poderia ser utilizada tanto para moer cana como milho; contudo, como não foi citada a presença de alambique na propriedade de Martinho Pires Farinho, podemos deduzir que o referido instrumento era utilizado para moer milho, já que esse produto aparecia com frequencia na época.

As análises dos inventários acima destacados indicam-nos que havia uma produção agrária diversificada na área Central de Minas. Essa diversificação englobava tanto a variedade de gêneros plantados quanto os seus destinos. Fica evidente, contudo, que essa diversidade não se situava na mesma região, pois a produção mais voltada para o mercado, encontramos nas proximidades entre a área Central e o Sul da Mata (cortada pelo Caminho Novo), ou então em locais onde existia algum produto de interesse do mercado, como a

\footnotetext{
${ }^{88}$ Vizinha ou dentro dos próprios limites da Freguesia de São Manoel, uma vez que o rio Xopotó, como indicamos no primeiro capítulo, situava-se nos limites entre as duas freguesias e, dependendo da área do Xopotó em questão, poderia situar-se dentro da Freguesia de São Manoel do Rio Pomba.

89 AHU-MG. A787/08/17. Cx. 127, doc. 03. Requerimento de Antônio Lopes de Moraes, morador na roça do Ribeirão de Santo Bento do Xopotó, Freguesia de Guarapiranga, solicitando à rainha a mercê de Ihe confirmar a doação, em sesmaria, de meia légua em terra, na paragem do Ribeirão de Santo Bento do Xopotó, Freguesia de Guarapiranga, termo da cidade de Mariana, fl. 02.

${ }^{90}$ AHU-MG. A777/02/13. Cx. 111, doc. 10. Requerimento do padre João Andrade da Mota, solicitando ao rei a mercê de lhe confirmar a doação, em sesmaria, de meia lega de terrana paragem do rio Xopotó, termo da cidade de Mariana, fl. 2.

${ }^{91}$ APM. Secretaria de Governo da Capitania (Seção Colonial). SC 234. Registro de sesmarias (com índice no final). Rolo 48, Gav. G-3, p. 183.

${ }^{92}$ Arquivo da Casa Setecentista. Livro de Registro de Testamentos n.o 75. Códice 160, auto 3317, fl. 13.
} 
poaia nas proximidades de São João Batista do Presídio ou mesmo na divisa com a região de Guarapiranga, isto é, relativamente próxima da área mineradora. Isso não implica em uma produção exclusivamente voltada para o autoconsumo no restante da área Central da Mata; indica apenas, com base nos inventários, que havia uma distribuição por região no ritmo da produção, o que não impedia que em outras áreas também houvesse alguma produção voltada para o mercado, especialmente local. Tais questões são relevantes para a análise dos conflitos, na medida em que eles eram mais frequentes nas áreas em que a produção era voltada para o mercado (e pagadora de Dízimos).

\section{CONSIDERAÇÕES FINAIS}

Percebe-se que o problema dos conflitos agrários na área Central da Zona da Mata de Minas Gerais, na segunda metade do século XVIII, esteve envolta com questões econômicas e administrativas importantes e que ambas encontravam-se profundamente entrelaçadas. A produção agrária, tão relevante como critério para solucionar disputas em torno da terra, indica-nos que a questão econômica não pode ser separada da seara políticoadministrativa. Evidentemente, os motivos eram distintos, pois, se por um lado a produção agrária para o sesmeiro era uma forma de sobrevivência (estando ou não diretamente associado ao mercado), ${ }^{93}$ por outro, isto é, pelo prisma da administração colonial, a referida produção significava possibilidades de arrecadação de tributos, o que em um contexto de crise fiscal era de suma relevância. Em outros termos, a produção agrária na sobredita área aparece como relevante, tanto para fins de demarcação de terras como também para fins fiscais, uma vez que era objetivo da administração colonial cobrar tributo (dízimos) para diminuir o impacto da queda da arrecadação com o tributo sobre o ouro, sem evidentemente, desistir da prospecção pelo vil metal, já que a conquista de uma área até então inóspita sempre abria a possibilidade de se encontrar novos veios auríferos.

A preocupação com a produção agrária inevitavelmente gerou conflitos, tanto entre sesmeiros quanto entre eles e os indígenas. A atuação da administração colonial nesses conflitos foi no sentido de mediar as disputas entre sesmeiros, procurando averiguar a legalidade da posse das partes em disputa; no tocante aos conflitos entre sesmeiros e indígenas, a mesma administração mostrou-se parcial, uma vez que pouco ou nada fez em relação aos abusos cometidos contra a tomada das terras indígenas.

A diferença na forma de atuação da administração colonial em relação aos conflitos agrários revela-nos a sua parcialidade, voltada mais para seus interesses próprios (entendidos como a garantia da arrecadação de tributos) do que para interferir na conquista das terras indígenas protagonizada pelos colonos. Quando os conflitos envolviam sesmeiros, percebemos que a administração colonial preocupou-se em referendar as Leis do Império Ultramarino Português, isto é, em garantir a posse das terras àqueles que estavam dentro

\footnotetext{
${ }^{93}$ Sobrevivência aqui é entendida como forma de produção material, valendo tanto para aquela produção voltada para o autoconsumo quanto para a que se destina ao mercado.
} 
dos limites das referidas leis e em punir (principalmente com a recusa das ações perpetradas pelos sesmeiros) aqueles que não estavam de acordo com a legislação da época. 